This archived file is not the final published version of the article.

The final published version is:

Hendrix D. Institutional self-citation rates: A three year study of universities in

the United States. Scientometrics. 2009;81(2):321-331.

DOI:10.1007/s11192-008-2160-2

Jointly published by Akadémiai Kiadó, Budapest

Scientometrics

and Springer, Dordrecht

DOI: $10.1007 / \mathrm{s} 11192-008-2160-2$

\title{
Institutional self-citation rates: A three year study of universities in the United States
}

\author{
DEAN HENDRIX \\ The State University of New York at Buffalo, Health Sciences Library, \\ 120-A Abbott Hall, Buffalo, NY 14214, USA
}

\begin{abstract}
Using Institute for Scientific Information (ISI) data, this paper calculated institutional self citations rates (ISCRs) for 96 of the top research universities in the United States from 2005-2007. Exhibiting similar temporal patterns of author and journal self-citations, the ISCR was $29 \%$ in the first year post-publication, and decreased significantly in the second year post-publication (19\%). Modeling the data via power laws revealed total publications and citations did not correlate with the ISCR, but did correlate highly with ISCs. California Institute of Technology exhibited the highest ISCR at $31 \%$. Academic and cultural factors are discussed in relation to ISCRs.
\end{abstract}

\section{Introduction}

Bibliometric statistics are used by institutions of higher education to evaluate the research quality and productivity of their faculty. With careers, funding, and individual, journal and institutional reputations at stake, the establishment of fair bibliometric indicators and standards has become vital. In light of this atmosphere, self-citations in all their forms, has created controversy among scholars. At the author level, categories of self-citations [BALDI, 1998; WHITE, 2001] and their statistical characteristics [FALAGAS \& KAVVADIA, 2006] have been examined in the scientific literature. Several researchers studied the influence of author self-citations - specifically, ramifications on the professional reputations of scholars [FOWLER \& AKSNES, 2007; HYLAND, 2003; LAWANI, 1982]; bibliometric measures such as journal impact factors [SEGLEN, 1997], Hirsch's $h$-index [KeLly \& JENNIONS, 2006; SCHREIBER, 2007A; 2007C] and Egghe's $g$-index [SCHREIBER, 2007B]; field mobility metrics [AUSLOOS \& AL., 2007; HELLSTEN \& AL., 2007]; and scholarly communication trends [GLÄNZEL \& AL., 2006]. Interpretations of the exact effect on scholarship and bibliometrics differed among researchers. Some scholars construed author self-citations as potentially detrimental to accurate bibliometric analysis [GAMI \& AL., 2004; MACROBERTS \& MACROBERTS, 1989; Persson \& BeCKMANN, 1995; VAn RAan, 1998]. Pointedly, Schreiber wrote that self-citations significantly alter authors' $h$-indices [KELLY \& JENNIONS, 2006;

Received September 5, 2008

Address for correspondence:

DEAN HENDRIX

E-mail: dhendrix@buffalo.edu

$0138-9130 /$ US $\$ 20.00$

Copyright (C) 2009 Akadémiai Kiadó, Budapest

All rights reserved 
SCHREIBER, 2007A; 2007C] and $g$-indices [SCHREIBER, 2007B ], thus manipulation of bibliometric indicators is a legitimate concern. Conversely, Engqvist and Frommen stated the removal of frivolous self-citations or even all author self-citations has a trivial effect on $h$-indices [ENGQVIST \& FROMMEN, 2008]. Other research demonstrated the important role self-citations play in identifying researchers' field mobility patterns (HELlSTEN \& AL., 2007) and establishing academic reputations [HYLAND, 2003]. Suggesting that the influence of self-citations was related to the scope of a study, two research papers argued that self-citations skew bibliometric indicators of individuals and small groups of researchers, but have negligible impact at the macro level. [AKSNES, 2003; THIJS \& GLÄNZEL, 2005].

The influence of journal-level bibliometric measures, such as the Institute for Scientific Information's (ISI) impact factor, inspired research on journal self-citations and their disciplinary impacts. Focusing on the inherent characteristics of journal selfcitations, Rousseau described journal self-citation rates over a ten year period [RousseaU, 1999]. Correlating journal impact factor and self-citation rates, Frandsen noted that a higher proportion of journal self-citations related to lower journal impact factors [FRANDSEN, 2007]. Tsay noted that journal self-citations may be associated with the age and publication frequency of a journal [TSAY, 2006]. This may occur due to the reliance on journal self-citations by journals in their nascent phases. As with individual self-citations, opinions regarding the impact of journal self-citations vary among scholars. Nisonger compared ISI journal impact factors and the ranks of journals with and without journal self-citations, and found that journal self-citations did not affect the rankings of the vast majority of journals studied. Thus, he concluded that the utility of journal impact factors as a collection development tool was not compromised by journal self-citations [NISONGER, 2000]. Due to correlative relationships between journal selfcitations and journal impact factor, the potential manipulation of journal impact factors by journal self-citations has been noted by several scholars [ANSEEL \& AL., 2004; DEMARIA, 2003; FASSOULAKI \& AL., 2000; MOTAMED \& AL., 2002].

Though studies concerning departmental or research group bibliometric characteristics were abundant, the author uncovered only one research study that significantly addressed self-citations in an institutional context. In studying the largest European universities, van Raan found significant negative correlations between universities' author self-citation rate and research performance, and an insignificant negative correlation between total number publications and the universities' author selfcitation rate [VAN RAAN, 2008A]. The author did not retrieve any studies specific to institutional self-citations (ISC) or institutional self-citation rates (ISCR).

An ISC is a citation that references works written by researchers employed at the citing author's institution, including his or her own research. Mathematically, the ISCR is defined the total number of ISCs divided by the total number of citations received by an institution's researchers times $100($ ISCR $=($ ISC / total citations received $) \times 100)$. 
According to Lawani's definition, the ISCR is the institution's diachronous selfcitedness rate [LAWANI, 1982]. Employing raw citation data gathered and synthesized from the Institute for Scientific Information's online citation index, Web of Science, this study intends to analyze the phenomenon of ISCs and ISCRs at top research universities in the United States from 2005-2007.

\section{Methodology}

Using the basic classification criteria from the Carnegie Commission on Higher Education Carnegie Classification, the study limited to doctorate-granting universities classified as research universities with "very high research activity" (n=96). In searching for research from specific universities, the author used broad searches in the Web of Science address field and limited to three years: 2005, 2006 and 2007. This data was searched during the week of December 2, 2007 through December 8, 2007 to avoid data inconsistencies due to database updates. The results of the search were subsequently refined by institution using the "Analyze Results" feature in Web of Science. The author exercised due diligence in capturing all possible name variants of a university (i.e., Univ N Carolina, UNC, Univ North Carolina) within Web of Science. For each university search, a citation report was run within Web of Science on the refined results set to gather and synthesize the following measures:

- the total number of published articles $(a)$

- the total number of citations to published articles $(c)$

- the total number of institutional self-citations (s, or ISC)

- the average number of citations per article $(c / a)$

- the average number of self-citation citations per articles $(s / a)$

- the institutional self-citation rate $(s / c$, or ISCR)

Due to the large number of articles published, the author could not run one citation report for Harvard University and the University of Texas at Austin. Articles and the accompanying citation data from these two institutions were harvested through several smaller searches, de-duplicated, totaled, and subsequently analyzed. Modeling the data via power laws, correlations between bibliometric measures were calculated.

\section{Results}

Data analysis

Overall, $19 \%$ of the collected citations were ISCs, and for the individual years studied, 2007, 2006 and 2005, the ISCRs were 28\%, 19\% and 18\%, respectively. Figure 1 and Figure 2 illustrate the temporal characteristics for ISCs and ISCRs for selected universities based on their ISCR percentiles. 
HENDRIX: Institutional self-citation rates

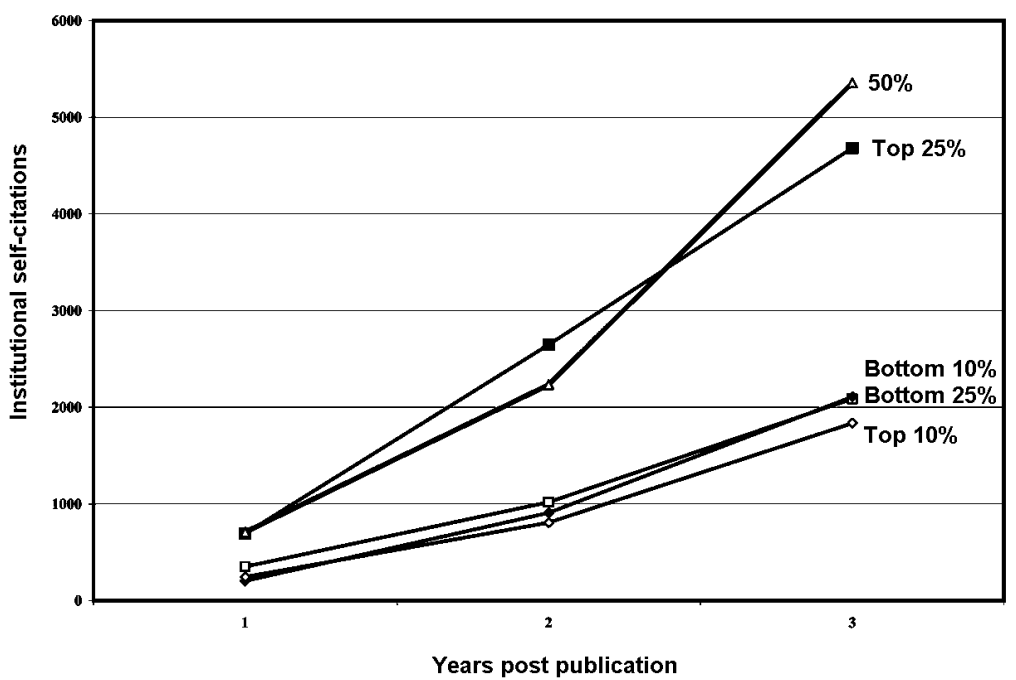

Figure 1. Institutional self-citations

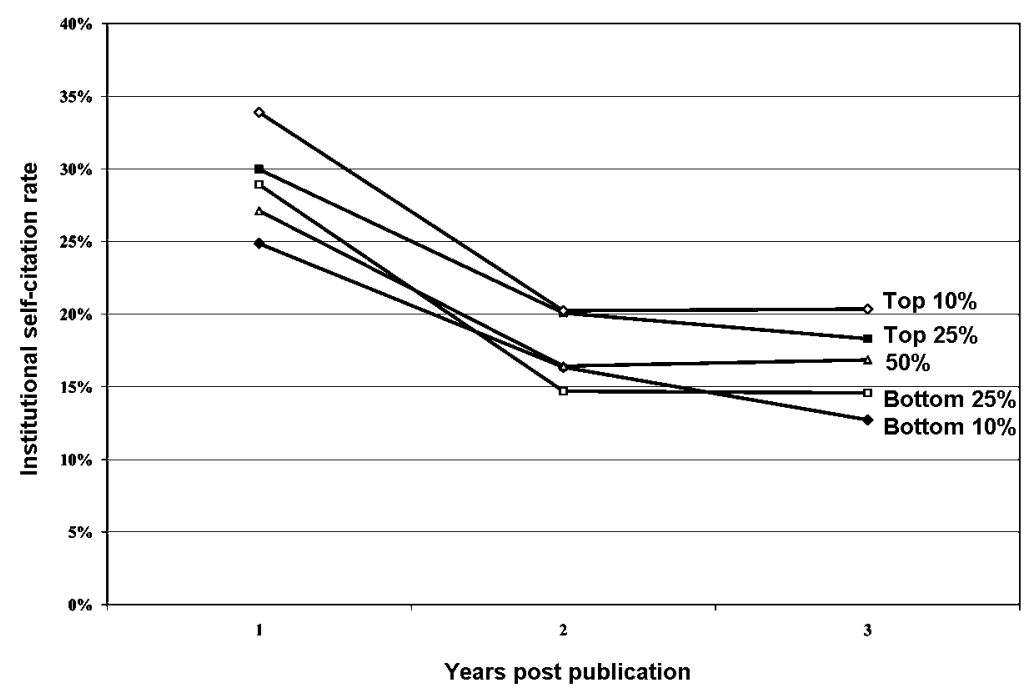

Figure 2. Institutional self-citation rates

Among the studied universities, the University of California-Riverside represented the ninetieth percentile (high ISCR); Ohio State University represented the seventy-fifth percentile; Washington University in St. Louis represented the median of the sample; 
the University of Illinois at Chicago represented the twenty-fifth percentile; and the University of Connecticut represented the tenth percentile (low ISCR).

For the aggregate, the ISCR was higher within the first year (mean $=28 \%, \mathrm{n}=96)$ than those published between one to three years ago (mean $=18 \%, \mathrm{n}=96)$. Moreover, universities demonstrated a higher ISCR within the first two years (mean $=20 \%, \mathrm{n}=96$ ) than the rate of articles older than 2 years (mean $=18 \%, \mathrm{n}=96$ ). Only one university, Brandeis University had a higher ISCR in year two than in year one, and twenty-six $(27 \%, \mathrm{n}=96)$ had a higher ISCR in year three than in year two. Due to the study's static population of papers, extramural citations diminished the ICSR over time.

The Appendix provides article, citation and ISCR data for the 96 universities studied, ranked by ISCR. The California Institute of Technology exhibited the highest ISCR of the studied schools by a wide margin. Table 1 shows the results of the power law analysis between the ISCR and other variables. Only two variables, total number of ISCs and average ISCs per article, showed significant correlative relationships with the ISCR. Raw totals of articles and citations did not correlate with an institution's ISCR, but correlated highly with the size-dependent measure, total number of ISCs $\left(\mathrm{R}^{2}=\right.$ 0.8622 for articles; $\mathrm{R}^{2}=0.9548$ for citations).

The size-independent measures, average citation per article, ISCR, and average selfcitations per article demonstrated the least amount of variance. However, size dependent measures demonstrated much more variance due to significant outliers in the population. Five universities exceeded three standard deviations from the mean, four positively (California Institute of Technology, Harvard University, Massachusetts Institute of Technology, and the University of Texas at Austin) and one negatively (University of Colorado at Denver and Health Sciences Center), in at least one of the studied indicators. The author did not remove the universities from the sample, but performed an alternate analysis of the data without the outliers $(n=91)$. Without the outliers, the author calculated lower $\mathrm{R}^{2}$ values and lower power law exponents for all studied variables and the ISCR. The results of the alternate analysis are presented in Table 1.

Table 1. Power law correlations of bibliometric variables with the ISCR

\begin{tabular}{lcccc}
\hline & \multicolumn{2}{c}{$\begin{array}{c}\text { All institutions } \\
(\mathrm{n}=96)\end{array}$} & \multicolumn{2}{c}{$\begin{array}{c}\text { Institution population without outliers } \\
(\mathrm{n}=91)\end{array}$} \\
\cline { 2 - 5 } Variable & $\mathrm{R}^{2}$ & Equation & $\mathrm{R}^{2}$ & Equation \\
\hline Articles & 0.1697 & $I S C R=0.0518 x^{0.1313}$ & 0.0543 & $I S C R=0.0983 \mathrm{x}^{0.0609}$ \\
Citations & 0.2110 & $I S C R=0.0474 \mathrm{x}^{0.1267}$ & 0.0664 & $I S C R=0.0936 \mathrm{x}^{0.0596}$ \\
ISC & 0.4066 & $I S C R=0.0478 \mathrm{x}^{0.1526}$ & 0.2039 & $I S C R=0.0766 \mathrm{x}^{0.0965}$ \\
Citations per Article & 0.1141 & $I S C R=0.1245 x^{0.3065}$ & 0.0293 & $I S C R=0.1494 \mathrm{x}^{0.1319}$ \\
ISC per Article & 0.6363 & $I S C R=0.2401 \mathrm{x}^{0.4637}$ & 0.4773 & $I S C R=0.2294 \mathrm{x}^{0.3905}$ \\
\hline
\end{tabular}




\section{Methodological limitations}

Due to the nature of Web of Science's data set and capabilities, limitations to this methodology existed. Omitting citation histories of thousands of journals, proceedings, technical reports and patents, Web of Science is not an exhaustive resource. Clearly, the longevity of ISC behaviors cannot be measured by the author due to the time frame studied. Broad in scope, this study did not account for unique disciplinary citation behaviors, so this data can not be extrapolated to represent ISCR of specific departments or research groups. The author conceded publications linked to institution names that were misspelled or used unfamiliar variants in the address field were not retrieved. Furthermore, Moed estimated that $7 \%$ of citations from ISI databases contain errors (H. F. MOED, 2002). No proportional attribution techniques were applied in the case of multiple authors from different institutions. Finally, the studied three year window does not adequately reveal the temporal nature of the ISCR, but may only describe immediate characteristics.

\section{Comparison to other studies}

The author did not discover studies explicitly addressing ISCRs, but did find similar research regarding author self-citations. In comparing this study's power law models with van Raan's analysis of European universities, the data showed that the number of publications positively influences the total number of self-citations at the largest United States universities at a greater rate than at the largest European universities. Van Raan also found that research performance negatively correlated with self-citation rates. Though research performance was not calculated in this study, some the United States' most prestigious institutions - California Institute of Technology, Harvard University, Princeton University, and Massachusetts Institute of Technology - exhibited some of the highest ISCRs. Both studies found the relationship between the total number of publications and self-citation rates insignificant, however, this study found a generally positive relationship (Table 2) and van Raan found the relationship to be negative (A. F. J. VAN RAAN, 2008a). This study also corroborates another van Raan study that concluded more publications produced at an institution increases ISCs at a higher rate than external citations based on power law exponents (A. F. J. VAN RAAN, 2008b). The author calculated a power law exponent of 1.24 for ISCs, and 1.09 for external citations.

If all fields are indexed correctly, the ISCR should be higher than the author selfcitation rate. In other self-citation studies, author self-citation rates are listed at various percentages - some much higher than this study's overall ISCR (D. W. AKSNES, 2003; P. O. SEgLEN, 1997); some much lower (K. HYLAND, 2003); and some very similar to the overall ISCR (M. E. FAlagas \& P. KAVVAdia, 2006; A. S. GAMI et al., 2004). Despite the limited three year window, the ISCR exhibits similar temporal patterns of 
author and journal self-citation rates. Namely, the highest rate of self-citation occurs within the first year of an article being published [ADAMS \& AL, 2004; AKSNES, 2006; MACZELKA \& ZSINDELY, 1992].

\section{Discussion}

The ISCR may lend insights into the recent academic culture of an institution, and may shed some light on the motivations of authors who cite authors from their own institutions. High ISCRs may indicate the presence of genuine "invisible colleges" within an institution, or negatively, intentional "citation circles" where researchers deliberately cite certain researchers for the express purpose of inflating bibliometric indicators (E. GARFIELD \& A. WellJAMS-DOROF, 1992). An institution's tenure and promotion rubric that overemphasizes citation indices may unintentionally incentivize individual self-citation, or the creation of "citation circles", thus exaggerating the ICSR. On the other hand, universities or departments within universities with excellent reputations may generate more legitimate self-citations. A highly focused or unique research orientation of an institution may manifest itself in the form of higher ISCRs. For instance, CalTech demonstrated a much higher ISCR, most probably due to the state-of-the-art research being done at specialized laboratories, such as the Jet Propulsion Laboratory. Furthermore, if specialized research groups or departments exist within a university in highly cited fields such as astronomy and astrophysics, the ISCR may rise. The social environment and intra-faculty familiarity may play a role, though institution size does not seem to make a difference in ISCRs. Universities with faculties that typically collaborate more, write longer articles and cite more extensively may influence the ISCR positively. It is doubtful that an insular academic culture may be to blame for a higher ICSR, due to the ease and frequency of extramural collaboration in the digital age. A university with a higher percentage of articles published in highly cited journals may also experience a high ISCR as these articles are more likely to be cited generally. Unique and emerging research topics may spawn specialty journals, which in their nascency may have a tendency to self-cite (H. MACZELKA \& S. ZSINDELY, 1992), consequently raising the ISCR for institutions that employ researchers in these areas.

\section{References}

Adams, J. D., Clemmons, J. R., Stephan, P. E. (2004), Standing on Academic Shoulders: Measuring Scientific Influence in Universities. Cambridge, MA: National Bureau of Economic Research, (NBER Working Paper No. 10875)

AKSNES, D. W. (2003), A macro study of self-citation, Scientometrics, 56 (2) : 235-246.

AKSNES, D. W. (2006), Citation rates and perceptions of scientific contribution, Journal of the American Society for Information Science and Technology, 57 (2) : 169-185. 
HENDRIX: Institutional self-citation rates

ANSEel, F., Duyck, W., De BAEne, W., Brysbaert, M. (2004), Journal impact factors and self-citations: Implications for psychology journals, American Psychologist, 59 (1) : 49-51.

Ausloos, M., Lambiotte, R., Scharnhorst, A., Hellsten, I. (2007), Andrzej Pekalski Networks of Scientific Interests with Internal Degrees of Freedom through Self-citation Analysis, Arxiv preprint arXiv:0710.1800.

BALDI, S. (1998), Normative versus social constructivist processes in the allocation of citations: A networkanalytic model, American Sociological Review, 63 (6) : 829-846.

DEMARIA, A. N. (2003), A report card for journals, Journal of the American College of Cardiology, 42 (5) : 952-953.

EngQvist, L., Frommen, J. G. (2008), The h-index and self-citations, Trends in Ecology \& Evolution, 23 (5) : 250-252.

FalaGas, M. E., KaVVAdia, P. (2006), "Eigenlob": self-citation in biomedical journals, FASEB Journal, 20 (8) : 1039-1042.

Fassoulaki, A., Paraskeva, A., Papilas, K., Karabinis, G. (2000), Self-citations in six anaesthesia journals and their significance in determining the impact factor, British Journal of Anaesthesia, 84 (2) : 266-269.

Fowler, J. H., AKSNES, D. W. (2007), Does self-citation pay? Scientometrics, 72 (3) : 427-437.

FRANDSEN, T. F. (2007), Journal self-citations - Analysing the JIF mechanism, Journal of Informetrics, 1 (1) : 47-58.

Gami, A. S., Montori, V. A., Wilczynski, N. L., HAynes, R. B. (2004), Author self-citation in the diabetes literature, Canadian Medical Association Journal, 170 (13) : 1925-1927.

GARFIELD, E., WelluAMS-Dorof, A. (1992), Citation data: their use as quantitative indicators for science and technology evaluation and policy-making, Science and Public Policy, 19 (5) : 321-327.

Glänzel, W., Debackere, K., ThiJs, B., Schubert, A. (2006), A concise review on the role of author selfcitations in information science, bibliometrics and science policy, Scientometrics, 67 (2) : 263-277.

Hellsten, I., Lambiotte, R., Scharnhorst, A., Ausloos, M. (2007), Self-citations, co-authorships and keywords: A new approach to scientists' field mobility? Scientometrics, 72 (3) : 469-486.

HYLAND, K. (2003), Self-citation and self-reference: Credibility and promotion in academic publication, Journal of the American Society for Information Science and Technology, 54 (3) : 251-259.

Kelly, C. D., Jennions, M. D. (2006), The h index and career assessment by numbers, Trends in Ecology \& Evolution, 21 (4) : 167-170.

LAWANI, S. M. (1982), On the heterogeneity and classification of author self-citations, Journal of the American Society for Information Science, 33 (5) : 281-284.

Macroberts, M. H., Macroberts, B. R. (1989), Problems of citation analysis: A critical review, Journal of the American Society for Information Science, 40 (5) : 342-349.

MACZELKA, H., ZsindELY, S. (1992), All well if starts well? Citation infancy of recently launched chemistry journals, Scientometrics, 25 (2) : 367-372.

Moed, H. F. (2002), The impact factors debate: the ISI's uses and limits, Nature, 415 (6873) : 731-732.

Motamed, M., Mehta, D., Basavaraj, S., Fuad, F. (2002), Self citations and impact factors in otolaryngology journals, Clinical Otolaryngology, 27 (5) : 318-320.

NisONGER, T. E. (2000), Use of the Journal Citation Reports for serials management in research libraries: An investigation of the effect of self-citation on journal rankings in library and information science and genetics, College \& Research Libraries, 61 (3) : 263-275.

Persson, O., BECKMANN, M. (1995), Locating the network of interacting authors in scientific specialties, Scientometrics, 33 (3) : 351-366.

Rousseau, R. (1999), Temporal differences in self-citation rates of scientific journals, Scientometrics, 44 (3) : 521-531.

SCHREIBER, M. (2007a), A case study of the Hirsch index for 26 non-prominent physicists, Annalen Der Physik, 16 (9) : 640-652.

SCHREIBER, M. (2007b), The influence of self-citation corrections on Egghe's $g$ index, Arxiv preprint arXiv:0707.4577.

SCHREIBER, M. (2007c), Self-citation corrections for the Hirsch index, Epl, 78 (3) : 6. 
SEGLEN, P. O. (1997), Citations and journal impact factors: Questionable indicators of research quality, Allergy: European Journal of Allergy \& Clinical Immunology, 52 (11) : 1050.

THus, B., GLÄNZEL, W. (2005), The influence of author self-citations on bibliometric meso-indicators. The case of European universities, Scientometrics, 66 (1) : 71-80.

TSAY, M. Y. (2006), Journal self-citation study for semiconductor literature: Synchronous and diachronous approach, Information Processing \& Management, 42 (6) : 1567-1577.

VAN RAAN, A. F. J. (1998), The influence of international collaboration on the impact of research results, Scientometrics, 42 (3) : 423-428.

VAN RAAN, A. F. J. (2008a), Bibliometric statistical properties of the 100 largest European research universities: Prevalent scaling rules in the science system, Journal of the American Society for Information Science and Technology, 59 (3) : 461-475.

VAN RAAN, A. F. J. (2008b), Self-citation as an impact-reinforcing mechanism in the science system, Arxiv preprint arXiv:0801.0524.

White, H. D. (2001), Authors as citers over time, Journal of the American Society for Information Science and Technology, $52(2): 87-108$ 
Appendix

Article, citation and ISCR data for selected United States universities, ranked by ISCR

\begin{tabular}{|c|c|c|c|c|c|c|}
\hline Research universities & $\begin{array}{c}\text { Total } \\
\text { articles }\end{array}$ & $\begin{array}{c}\text { Total } \\
\text { citations }\end{array}$ & Total ISC & $\begin{array}{c}\text { Average } \\
\text { citations } \\
\text { per article }\end{array}$ & $\begin{array}{c}\text { Average } \\
\text { ISC } \\
\text { per article }\end{array}$ & ISCR \\
\hline California Institute of Technology & 8862 & 47958 & 14787 & 5.41 & 1.67 & $30.83 \%$ \\
\hline Harvard University & 43458 & 228110 & 56950 & 5.25 & 1.31 & $24.97 \%$ \\
\hline Pennsylvania State University & 14991 & 42245 & 10316 & 2.82 & 0.69 & $24.42 \%$ \\
\hline Princeton University & 8227 & 31529 & 7563 & 3.83 & 0.92 & $23.99 \%$ \\
\hline University of Arizona & 11884 & 36710 & 8718 & 3.09 & 0.73 & $23.75 \%$ \\
\hline Carnegie Mellon University & 4672 & 13475 & 3153 & 2.88 & 0.67 & $23.40 \%$ \\
\hline Iowa State University & 6935 & 16913 & 3834 & 2.44 & 0.55 & $22.67 \%$ \\
\hline University of California-Santa Cruz & 3259 & 16049 & 3623 & 4.92 & 1.11 & $22.57 \%$ \\
\hline Massachusetts Institute of Technology & 10457 & 66625 & 14731 & 6.37 & 1.41 & $22.11 \%$ \\
\hline University of California-Riverside & 4888 & 13733 & 2887 & 2.813 & 0.59 & $21.02 \%$ \\
\hline University of Hawaii at Manoa & 5659 & 16959 & 3565 & 3.00 & 0.63 & $21.02 \%$ \\
\hline Rice University & 3365 & 10933 & 2287 & 3.25 & 0.68 & $20.92 \%$ \\
\hline University of California-Santa Barbara & 6761 & 25560 & 5313 & 3.78 & 0.79 & $20.79 \%$ \\
\hline Johns Hopkins University & 24877 & 95442 & 19745 & 3.84 & 0.79 & $20.69 \%$ \\
\hline SUNY at Albany & 2832 & 6803 & 1395 & 2.40 & 0.49 & $20.51 \%$ \\
\hline University of Notre Dame & 3997 & 11072 & 2263 & 2.77 & 0.57 & $20.44 \%$ \\
\hline Texas A \& M University & 12380 & 26072 & 5317 & 2.11 & 0.43 & $20.39 \%$ \\
\hline University of California-Berkeley & 18150 & 70642 & 14377 & 3.89 & 0.79 & $20.35 \%$ \\
\hline Michigan State University & 9579 & 21848 & 4444 & 2.28 & 0.46 & $20.34 \%$ \\
\hline Purdue University & 10393 & 22479 & 4566 & 2.16 & 0.44 & $20.31 \%$ \\
\hline University of Texas at Austin & 45878 & 148254 & 29863 & 3.23 & 0.65 & $20.14 \%$ \\
\hline University of Illinois at Urbana-Champaign & 12003 & 30805 & 6098 & 2.57 & 0.51 & $19.80 \%$ \\
\hline University of California-Los Angeles & 25629 & 84387 & 16673 & 3.29 & 0.65 & $19.76 \%$ \\
\hline Ohio State University & 15730 & 41115 & 8025 & 2.61 & 0.51 & $19.52 \%$ \\
\hline University of Washington-Seattle Campus & 23283 & 87860 & 16762 & 3.77 & 0.72 & $19.08 \%$ \\
\hline Colorado State University & 5411 & 13084 & 2495 & 2.42 & 0.46 & $19.07 \%$ \\
\hline University of Michigan-Ann Arbor & 25042 & 76859 & 14536 & 3.07 & 0.58 & $18.91 \%$ \\
\hline University of Wisconsin-Madison & 21598 & 58082 & 10900 & 2.69 & 0.50 & $18.77 \%$ \\
\hline Rensselaer Polytechnic Institute & 2624 & 6488 & 1211 & 2.47 & 0.46 & $18.67 \%$ \\
\hline Oregon State University & 4905 & 10385 & 1908 & 2.12 & 0.39 & $18.37 \%$ \\
\hline University of Pennsylvania & 21870 & 75421 & 13832 & 3.45 & 0.63 & $18.34 \%$ \\
\hline University of Cincinnati & 8512 & 23944 & 4391 & 2.81 & 0.52 & $18.34 \%$ \\
\hline University of California-San Diego & 17674 & 67604 & 12329 & 3.83 & 0.70 & $18.24 \%$ \\
\hline University of Chicago & 12199 & 43129 & 7837 & 3.54 & 0.64 & $18.17 \%$ \\
\hline Yale University & 17120 & 62601 & 11275 & 3.66 & 0.66 & $18.01 \%$ \\
\hline University of Pittsburgh & 18764 & 55824 & 10043 & 2.98 & 0.54 & $17.99 \%$ \\
\hline Arizona State University & 6923 & 14442 & 2591 & 2.09 & 0.37 & $17.94 \%$ \\
\hline Duke University & 17596 & 60241 & 10781 & 3.42 & 0.61 & $17.90 \%$ \\
\hline Georgia Institute of Technology & 7497 & 17733 & 3161 & 2.37 & 0.42 & $17.83 \%$ \\
\hline University of Tennessee & 9198 & 22236 & 3951 & 2.42 & 0.43 & $17.77 \%$ \\
\hline University of Kentucky & 7630 & 17160 & 3043 & 2.25 & 0.40 & $17.73 \%$ \\
\hline Vanderbilt University & 11137 & 36799 & 6524 & 3.30 & 0.59 & $17.73 \%$ \\
\hline University of Florida & 17219 & 37173 & 6551 & 2.16 & 0.38 & $17.62 \%$ \\
\hline University of California-Irvine & 9907 & 32283 & 5679 & 3.26 & 0.57 & $17.59 \%$ \\
\hline Stanford University & 21320 & 79824 & 13998 & 3.74 & 0.66 & $17.54 \%$ \\
\hline University of Minnesota & 19273 & 52424 & 9142 & 2.72 & 0.47 & $17.44 \%$ \\
\hline University of Maryland & 17419 & 46137 & 8033 & 2.65 & 0.46 & $17.41 \%$ \\
\hline Virginia Polytechnic Institute and State University & 5920 & 10083 & 1747 & 1.70 & 0.30 & $17.33 \%$ \\
\hline Washington University in St. Louis & 13516 & 48026 & 8299 & 3.55 & 0.61 & $17.28 \%$ \\
\hline Cornell University & 17410 & 55566 & 9588 & 3.19 & 0.55 & $17.26 \%$ \\
\hline Wayne State University & 7507 & 18417 & 3154 & 2.45 & 0.42 & $17.13 \%$ \\
\hline Northwestern University & 14308 & 44627 & 7555 & 3.12 & 0.53 & $16.93 \%$ \\
\hline Kansas State University & 3267 & 5823 & 984 & 1.78 & 0.30 & $16.90 \%$ \\
\hline
\end{tabular}




\begin{tabular}{|c|c|c|c|c|c|c|}
\hline Research universities & $\begin{array}{c}\text { Total } \\
\text { articles }\end{array}$ & $\begin{array}{c}\text { Total } \\
\text { citations }\end{array}$ & Total ISC & $\begin{array}{c}\text { Average } \\
\text { citations } \\
\text { per article }\end{array}$ & $\begin{array}{l}\text { Average } \\
\text { ISC } \\
\text { per article }\end{array}$ & ISCR \\
\hline University of Colorado at Boulder & 15126 & 50844 & 8559 & 3.36 & 0.57 & $16.83 \%$ \\
\hline Columbia University in the City of New York & 20259 & 69247 & 11655 & 3.42 & 0.58 & $16.83 \%$ \\
\hline SUNY at Stony Brook & 6331 & 19164 & 3216 & 3.03 & 0.51 & $16.78 \%$ \\
\hline University of Massachusetts & 10888 & 32691 & 5460 & 3.00 & 0.50 & $16.70 \%$ \\
\hline University of California-Davis & 16106 & 41585 & 6878 & 2.58 & 0.43 & $16.54 \%$ \\
\hline Montana State University & 1849 & 4021 & 663 & 2.17 & 0.36 & $16.49 \%$ \\
\hline University of Iowa & 10073 & 26797 & 4401 & 2.66 & 0.44 & $16.42 \%$ \\
\hline Florida State University & 4908 & 10936 & 1783 & 2.23 & 0.36 & $16.30 \%$ \\
\hline Rutgers University & 8880 & 21289 & 3447 & 2.40 & 0.39 & $16.19 \%$ \\
\hline Indiana University & 13506 & 31254 & 5059 & 2.31 & 0.37 & $16.19 \%$ \\
\hline North Carolina State University at Raleigh & 7072 & 13838 & 2226 & 1.96 & 0.31 & $16.09 \%$ \\
\hline University of North Carolina & 18458 & 53281 & 8546 & 2.89 & 0.46 & $16.04 \%$ \\
\hline University of Georgia & 7351 & 15565 & 2493 & 2.12 & 0.34 & $16.02 \%$ \\
\hline Brandeis University & 1580 & 5651 & 900 & 3.58 & 0.57 & $15.93 \%$ \\
\hline University of Virginia & 9636 & 27939 & 4430 & 2.90 & 0.46 & $15.86 \%$ \\
\hline University of Nebraska & 7648 & 14192 & 2242 & 1.86 & 0.29 & $15.80 \%$ \\
\hline University of Delaware & 4482 & 9071 & 1431 & 2.02 & 0.32 & $15.78 \%$ \\
\hline Washington State University & 4602 & 9561 & 1497 & 2.08 & 0.33 & $15.66 \%$ \\
\hline University of New Mexico & 5642 & 14600 & 2248 & 2.59 & 0.40 & $15.40 \%$ \\
\hline University of Illinois at Chicago & 9505 & 22483 & 3458 & 2.37 & 0.36 & $15.38 \%$ \\
\hline University of Rochester & 8129 & 26621 & 4055 & 3.27 & 0.50 & $15.23 \%$ \\
\hline Tufts University & 7069 & 24318 & 3659 & 3.44 & 0.52 & $15.05 \%$ \\
\hline University of South Carolina & 7558 & 21125 & 3155 & 2.80 & 0.42 & $14.93 \%$ \\
\hline University of Alabama at Birmingham & 9543 & 26937 & 4012 & 2.82 & 0.42 & $14.89 \%$ \\
\hline Brown University & 7130 & 20317 & 3017 & 2.85 & 0.42 & $14.85 \%$ \\
\hline Louisiana State University & 8623 & 18242 & 2688 & 2.12 & 0.31 & $14.74 \%$ \\
\hline University of Kansas & 6002 & 12834 & 1879 & 2.14 & 0.31 & $14.64 \%$ \\
\hline New York University & 12155 & 35957 & 5245 & 2.961 & 0.43 & $14.59 \%$ \\
\hline Emory University & 11998 & 35077 & 5105 & 2.92 & 0.43 & $14.55 \%$ \\
\hline University of Utah & 9643 & 26990 & 3926 & 2.80 & 0.41 & $14.55 \%$ \\
\hline SUNY at Buffalo & 5692 & 13331 & 1937 & 2.34 & 0.34 & $14.53 \%$ \\
\hline Boston University & 10731 & 34184 & 4859 & 3.19 & 0.45 & $14.21 \%$ \\
\hline University of Miami & 7060 & 18568 & 2636 & 2.63 & 0.37 & $14.20 \%$ \\
\hline Tulane University & 3844 & 9824 & 1387 & 2.56 & 0.36 & $14.12 \%$ \\
\hline University of Connecticut & 8903 & 22983 & 3222 & 2.58 & 0.36 & $14.02 \%$ \\
\hline University of Southern California & 11170 & 29844 & 4151 & 2.67 & 0.37 & $13.91 \%$ \\
\hline University of Missouri & 10297 & 18415 & 2408 & 1.79 & 0.23 & $13.08 \%$ \\
\hline University of South Florida & 5542 & 11902 & 1543 & 2.15 & 0.28 & $12.96 \%$ \\
\hline Case Western Reserve University & 8416 & 26064 & 3375 & 3.10 & 0.40 & $12.95 \%$ \\
\hline Dartmouth College & 4975 & 15823 & 2040 & 3.18 & 0.41 & $12.89 \%$ \\
\hline Georgetown University & 5238 & 12081 & 1400 & 2.31 & 0.27 & $11.59 \%$ \\
\hline Yeshiva University & 1156 & 4932 & 451 & 4.27 & 0.39 & $9.14 \%$ \\
\hline University of Colorado at Denver and Health Sciences Center & 856 & 1807 & 83 & 2.11 & 0.10 & $4.59 \%$ \\
\hline
\end{tabular}

